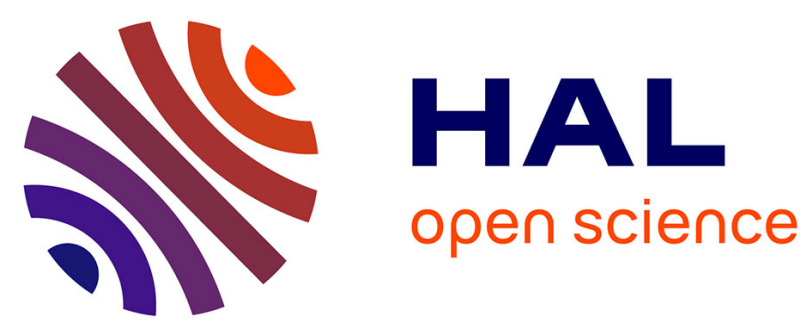

\title{
Modular Grouping Exploration to design Remanufacturable Products
}

Nicolas Tchertchian, Dominique Millet, Olivier Pialot

\section{To cite this version:}

Nicolas Tchertchian, Dominique Millet, Olivier Pialot. Modular Grouping Exploration to design Remanufacturable Products. 18th CIRP International Conference on LCE, CIRP, May 2011, Braunschweig, Germany. pp.413 - 418, 10.1007/978-3-642-19692-8_71 . hal-01401967

\section{HAL Id: hal-01401967 \\ https://hal.science/hal-01401967}

Submitted on 24 Nov 2016

HAL is a multi-disciplinary open access archive for the deposit and dissemination of scientific research documents, whether they are published or not. The documents may come from teaching and research institutions in France or abroad, or from public or private research centers.
L'archive ouverte pluridisciplinaire HAL, est destinée au dépôt et à la diffusion de documents scientifiques de niveau recherche, publiés ou non, émanant des établissements d'enseignement et de recherche français ou étrangers, des laboratoires publics ou privés. 


\title{
Modular Grouping Exploration to design Remanufacturable Products
}

\author{
Nicolas Tchertchian ${ }^{1}$, Dominique Millet ${ }^{1}$, Olivier Pialot ${ }^{1}$
}

${ }^{1}$ LISMMA - "Ecodesign and Optimization of Product" Laboratory, SUPMECA Toulon, Toulon, France

\begin{abstract}
One of the challenges of this decade is to rationalize the consumption of global resources while increasing economic activity. Remanufacturing is an option to this challenge; however this end of life strategy must be optimized. The information collected from a franking machine manufacturer, which has set up a refurbishment activity of its machines, has allowed us to qualify remanufacturing as a home-made process in many cases. This paper focuses on aspects of product Architecture.

The purpose of the approach proposed in this paper is to reorganize the classical architectures towards modular architectures allowing a much more industrialized remanufacturing.

Keywords:
\end{abstract}

Lifecycle design; Modular design; Remanufacturing

\section{INTRODUCTION}

The environmental problems caused by the emergence of new markets and the fast development of the goods consumption require a rationalization of the world resources consumption while maintaining an economic activity increasing. To reach this objective, the remanufacturing is a process of restoring a discarded product (at the end of the lifetime) in an equivalent functional state to a new product. [1] [2]

This definition constrained the architecture of the new product to take into account the operations relating to the remanufacturing defined by Steinhilper [3] or Sundin [4] such as dismantling, cleaning, the inspection, the sorting, the reconditioning and the reassembly. The modularization of the product is a way to allow the optimization of the operations related to the product end-of-life like the reutilisability, recycling, maintainability and the technological update [5]. In the literature, the modularization of the products forms part of the DfX approaches. "Design for Modularity" is an approach aiming at subdividing a system in smaller parts which can be created in an independent way and then used in various systems. In addition to the reduction of the costs, the modularity offers flexibility in the design (the addition of new technical solutions).

The goal of this paper is to propose to the designer potential Product Architectures (pPA) containing modules remanufacturables, recyclables and upgradable. Three levels of improvement of architecture are distinguished: (Optimization, improvement and innovation) correspondent with various evolutions of use: necessary functions, Short term upgradable functions and Long term upgradable functions).

This article is structured in the following way. In section 2, we introduce requirements of the remanufacturing on product architecture. In section 3, we define contours of the method. In section 4, we explain the operation of MGE tool. Section 5 examines validity of the approach with a case study. Finally section 6 concludes this study and positions the tool inside a more global methodology.

\section{PRODUCT ARCHITECTURES REQUIREMENTS FOR}

\section{REMANUFACTURING}

\subsection{Design For Remanufacturing}

The literature shows a growing interest for the remanufacturing [1], [3]. The definition of the remanufacturing [2] implies several design fields such as the evaluation of remanufacturability, re-design of product to facilitate the remanufacturing processes [6], [7], [8], the research on the necessary operation to refurbish product (dismantling, cleaning, inspection and sorting, reconditioning and re-assembly) [1], [3], environmental [9] and economic [10], [11] assessment.

The majority of these publications treat often one aspect of this very vast field. Many research works [12], [13], [14] relate to the means to set up to optimize the dismantling of the products for their valorization. Complexity increase with the number of components and time necessary for dismantling depends on many parameters (interconnection between the components, types of fixing, direction of dismantling, etc.)

The complete dismantling of a product quickly would be not easily justifiable from an economic point of view. In fact the remanufacturing must consider several criteria because, as Kara underlines it [15], «full disassembly of product tends to be unproductive due to technical and cost constraint». Zuidwijk insists " a product recovery strategy determines the degree of disassembly of a product and the assignment of recovery options" [16]. For him four options of valorization coexist:

- The remanufacturing on a component level (requiring a complete disassembling of the product)

- Recycling after complete disassembling of the product

- Recycling after partial disassembling of the product (to respect quotas)

- $\quad$ And the setting in discharge

It will be noted that the option which would privilege an optimized dismantling of the product to re-use modules having an addedvalue is not mentioned. In 2002, Lambert introduces the concept of incomplete dismantling [13] justified by certain technical constraints: irreversible connections, economic constraints (since the costs of 
dismantling are inversely proportional to the profit generated by the re-use of the components extracted). By using CAD software, it is possible to determine if the disassembling of a part is blocked by another

\subsection{Design For Modularity}

A new field emerges in answer to the need to carry out an intelligent and advantageous dismantling: "Design for Modularity". The modularization of the products is the first step towards a sustainable design [17]. The modular products make it possible to improve valorization of materials by differentiating the modules which are potentially recyclable and which are not recoverable [18]

The design of the future products will have to take into account the definition of the modules and Product Architecture. Today most of product on the market does not have a clearly defined module. So the evaluation of the end-of-life scenarios is more complicated. In the products having a high number of components, sub-units can be defined as functional group of the product (example of the washing machine [18]).

A modular decomposition is a means to optimize dismantling and to make more profits on the economic and environmental aspects. The remanufacturing makes it possible to re-use products or modules on several cycles according to the requirements of the consumer or the market evolution (update of the computers) [17]. Tomiyama [19] proposes the concept of "Post Mass Paradigm Production" to reduce the consumption of the natural resources as well as the production of waste by maintaining the standard of living or by improving it.

The satisfaction of this new model passes by an increase of the modules lifespan but the consequences are the functiona obsolescence of the product. The increase of product lifetime as well as the limitation of obsolescence requires to establish a strategy adapted to the value of product (repair, update, re-use, etc.): "Longer-life products should have functional upgradability besides reliability and fault-tolerance" [20] [5].

In the literature the benefits of the adoption of a modular approach in the product life cycle are less discussed. The product is not any more the result of a material assembly and a manufacturing process but a sum of inter-connected modules playing the role of central unit in the product modeling [21]. Thus in the model developed by Gehin [9] the product is composed of modules following the strategies of valorization on several cycles of use. Its approach allows an environmental evaluation of the product from these modules but by considering the operational costs on several cycles (supply chain, refurbishing...).

Kimura [18] and Umeda [5] propose methods to design modular product depending on modules characteristics as life cycle options and geometrical information. Considering the product life cycle, the components which undergo the same life cycle should be gathered in a module. These modules can then undergo refurbishing and recycling processes without disassembling. Then, the management of the components throughout the life cycle is optimized and to the environmental impact and the costs of logistics and recovery are reduced. According to established criteria, impacting on the life cycle of the product, various modules can be defined. The result of modular grouping is a variety of product architectures.

It is the choice among this variety which poses problem; selected architecture must answer to impact reduction and costs controls requirements while the technical criteria are satisfied.

\section{METHOD TO DEFINE POTENTIAL PRODUCT ARCHITECTURE OF REMANUFACTURABLE SYSTEM}

\subsection{The general principles of the methods}

The general principles of our approach relate to the definition of Product Architecture concept, the integration of new uses/upgradability, the calculation of the environmental/economic evaluation and the concept of affinity.

What is the definition of product architecture?

"Product architecture is the scheme by which the function of a product is allocated to physical components" [22]

«Each level in the product hierarchy has its architecture. Depending on the type of components, we speak about a functional, technology or physical architecture» [23]

"The Product architecture is « a comprehensive description of a bundle of product characteristics, including number and type of components and number and type of interface of those components » [24]

By convention, we define Product Architecture as:

Current Product Architecture $=\sum$ Current Module $i$

With Current Module $=\sum$ Component $j$

In the current product, the modules defined are "virtual" and depend on the function fulfilled.

Architecture Nouveau Produit $=\sum$ Module Actuel $i-\sum$ Composant $j+\sum$ Nouveau Composant $k$

The goal of the methodology is to suggest a more evolutive Product Architectures and taking account of new uses, new technologies, the new regulations...

Integration of new usages associated with new functionalities Upgradability

\begin{tabular}{|l|l|l|}
\hline Criteria & Parametric Upgrade & Functional Upgrade \\
\hline Integration & $\begin{array}{l}\text { Planned, } \\
\text { By substitution of module }\end{array}$ & $\begin{array}{l}\text { No planned } \\
\text { By externalisation of module }\end{array}$ \\
\hline Cost & Low & High \\
\hline Incertitude & Low & High \\
\hline Innovation & $\begin{array}{l}\text { Enhanced Functions } \\
\text { New functions }\end{array}$ & $\begin{array}{l}\text { Enhanced Functions } \\
\text { Innovative Functions }\end{array}$ \\
\hline$\ldots$ & & \\
\hline
\end{tabular}

Table 1: Functionalities extension.

Economic and environmental assessment

Environmental evaluation: The Environmental Impact (EI) uses to evaluate the modules corresponds to the Extraction/Manufacture Impact.

Economic evaluation: The economic Costs $(C)$ taking into account are the price of the modules.

Concept of affinity

Affinity is a Potential of interaction between two modules (or submodules) according to certain criteria.

According to the literature to improve modular architecture of a product it is necessary to gather modules (or components).

"Considering a whole life cycle of a product, components that undergo the same life cycle processes should be grouped into one module for improving, e.g., disassemblability, maintainability, upgradability, reusability, and recyclability" [5]

Types of grouping proposed in the paper:

- $\quad$ Grouping between modules recyclables

- Grouping between modules remanufacturables

- $\quad$ Grouping between modules upgradables 
MACPMR Methodology [25] is based on criteria which make it possible to gather modules having the same properties. Among these criteria:

- Reliability / Maintainability

- Technical and visual obsolescence

- Product range

\subsection{Preliminary definition of the Modules}

The method depends on an algorithm (Figure 1) allowing a characterization of the modules in pMR (i.e. Module potentially Remanufacturable), in pMr (i.e. Module potentially recyclable) and in intermediate modules pMU (i.e. module potentially Undefined which characterizes remanufacturables and/or recyclables modules). These modules can contain components which can be recycled and others remanufacturables (these modules pMU will be broken up in the stage of optimization into Sub-Modules SM so that there remain only $\mathrm{pSMR}$ and $\mathrm{pSMr}$ ).

In order to classify each module identified, the environmental and economic criteria were selected because they make it possible to explain, qualitatively in first time, the true concerns in industry: decrease the environmental impacts (to respect the regulations more and more severe) and increase the profits. The characterization of the modules is done according to the distribution of the costs and the impacts of the product. The cost price was used to characterize the economic costs of the module, while the environmental impact is characterized by impact in the extractionmanufacture phases; this methodological choice (focusing on the Pre-life and not on the whole life cycle) makes it possible on the one hand to simplify the problem and on the other hand to identify objectively the strongest economico-environmental improvement source.

\subsection{Modules organization}

This stage makes it possible to determine quantitatively the main "potential" modules of the product. These potential modules (pMR or pMr) are groupings of evaluated modules then identified like remanufacturables or recyclable with the sub-modules resulting from the decomposition of the modules pMU (in homogeneous submodules $r$ or $R$ ) in preliminary definition of modules. The modular grouping is based on calculation of affinity coefficient between modules (pMR or pMr), between sub-modules or modules and submodules. This affinity (eq. 1) contains 3 components presented in 3.1 like "Product criteria" influencing the remanufacturing: affinity of reliability (eq. 2), affinity of obsolescence (eq. 3) and affinity of commonality (eq.4). The purpose of this affinity is to privilege the groupings between modules whose coefficients are strongest.

Affinity $=\alpha \cdot A_{r e l}+\beta \cdot A_{o b s}+\gamma \cdot A_{c o m}$

The state of the art as of the applications carried out on an industrial case allow to privilege three criteria [5], [26]. Decomposition of affinity in several components at two strong points:

- An aggregate score allows an evaluation and an interpretation of the results more adapted for a use of the tool by a multidisciplinary team.

- The other advantage is the possibility to add weighting coefficients for each criteria, thus making it possible to better take into account particular strategies (for example: to support the grouping of the unreliable components in order to simplify the replacement of the module).

Characterization of grouping criteria:

$$
\text { - Reliability: }
$$

Data input: $M T B F$ of existing Component in Modules.

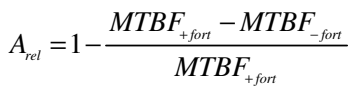

- Obsolescence:

Obsolescence is evaluated qualitatively according technologies evolution [5] and usages of the consumers.

Data input: $V L T$ of existing Component in Modules. $V L T$ is defined by Umeda [5] and is calculated by Tool [27] in MacPMR [25].

$A_{o b s}=1-\frac{V L T_{+ \text {fort }}-V L T_{-f o r t}}{V L T_{+ \text {fort }}}$

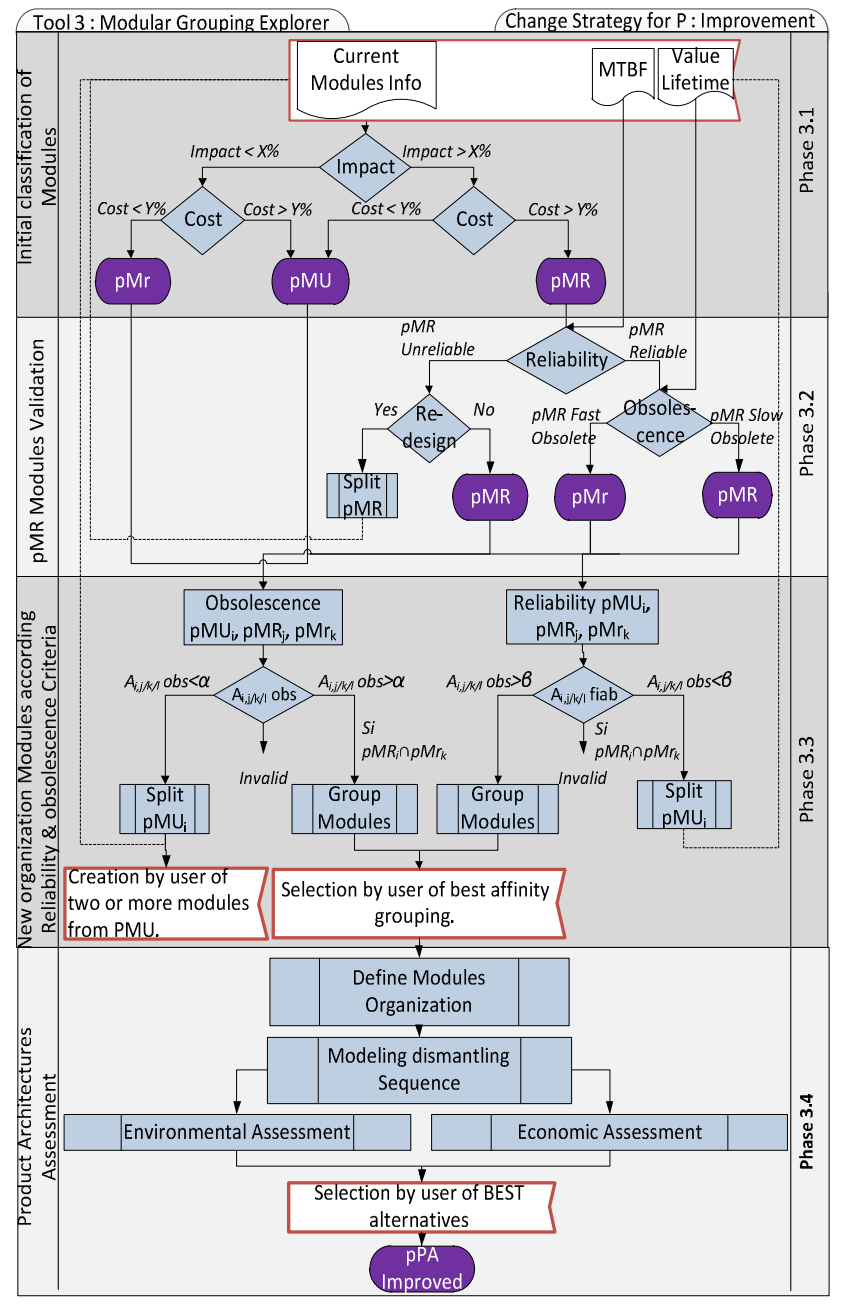

Figure 1 : Flowchart of method.

- Commonality:

Data input: The number of product in the range and the contents of each product in the range.

$A_{\text {com }}$ is the affinity of commonality between modules $i$ and $j$, and $p$ is the number of product in the range.

$$
A_{\text {com }}=\frac{\sum_{k=1}^{p} \alpha_{i j}^{k}}{p}
$$

If $i$ and $j=k$ then $\alpha=1$ else $\alpha=0$

The last stage of methodology is the validation of the pMR and pMr groupings. This stage is carried out by a control of functional compatibility of all the modules between them (materials, energy and information flow). This control must be carried out by the means of a block function functional diagram (functional analysis) 
because one does not need only the presence of a component blocks the operation of the module and/or the product.

When they are an incompatibility (low affinity), the grouping is not validated. It is necessary to make iteration in eliminating the component (or Sub-module) from the grouping and to compose a new grouping by a new affinity calculation.

For more flexibility, design team has liberty of freedom to modify the Sub-modules (by optimizing materials, or connections...) and to make them compatible with the pMR or pMr.

\subsection{Assessment of Product Architectures}

The early phases of the tool allow the designer to have a large panel of modules, according to the selected sensitivity for each criterion: reliability, obsolescence and commonality. In the last phase the designer is assisted in his choice of one or more architectures. The choice of architectures depends on two criteria. First is economic, it takes into account the cost of the disassembly operations compared to the retail prices of the modules (or of the constitutive components). And second is environmental, the choice of architectures takes into account the impact of the modules in Extraction and Manufacture phase. The designer establishes, for each list of modules, various organizations helped by function block diagram (Figure 2) with information flows between modules. The objective is to chart the sequence of dismantling simply so as to withdraw in priority the pMR without disassembling the pMr. To calculate the time of dismantling it is necessary to provide information: type of connections, orientation of dismantling, accessibility, ect. The means used to estimate times of dismantling is the Prodtect software.

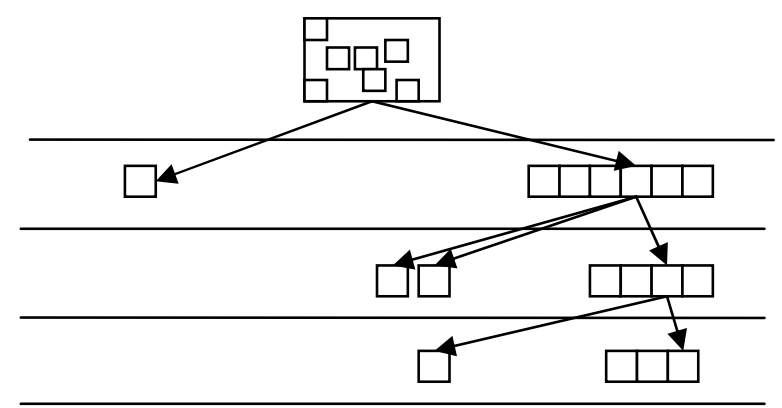

Figure 2 : Dismantling sequence.

The disassembly cost of the pMR is given by:

$C_{\text {dis }}=\sum_{i=1}^{n} t_{p M R i} \times C_{p M R i}$

For the environmental criteria, the designer calculates the impact generated during materials extraction and manufacture of modules. Avoided impact defines environmental impact for pMR and generated impact defines environmental impact for pMr. Solutions are compared with their Environmental Gain.

\section{MODULAR GROUPING EXPLORER ON CASE STUDY}

The case study considered the strategy improvement.

\subsection{Initial classification of the Modules}

In order to show the various steps of the proposed approach, a mechatronic product is considered (Figure 3), made up of 11 modules, marketed in the leasing form.

According to the strategy of change wished by the user, the input data table is updated (Table 1). In improvement strategy only the two criteria Reliability and obsolescence, are used.

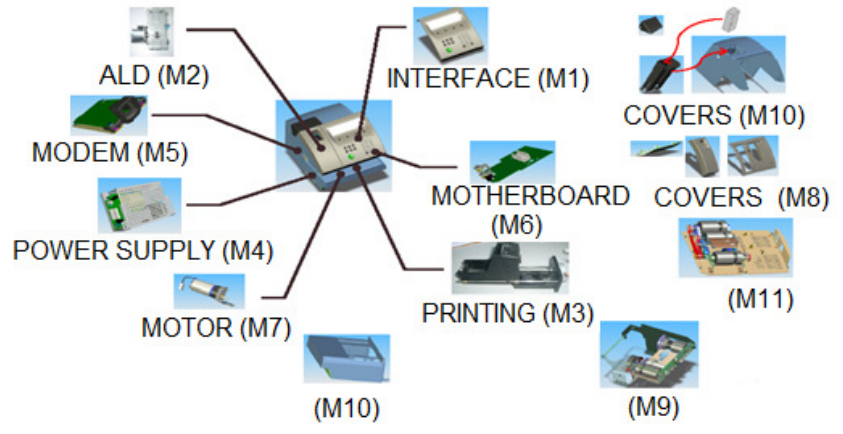

Figure 3 : Franking machine's Modules

\begin{tabular}{|c|c|c|c|c|c|c|c|}
\hline \multicolumn{8}{|c|}{ INPUT DATA } \\
\hline $\mathbf{N}^{\circ}$ & $\begin{array}{c}\text { Modules' } \\
\text { listing }\end{array}$ & $\begin{array}{c}\text { Environmental } \\
\text { Impact }\end{array}$ & $\begin{array}{c}\text { Production } \\
\text { Cost }\end{array}$ & MTBF & MTBF $^{+}$ & VLT & $\mathrm{VLT}^{+}$ \\
\hline M1 & $\begin{array}{c}\text { User } \\
\text { Interface }\end{array}$ & 28,30 & 12,00 & 25 & 30 & 4 & 8 \\
\hline M2 & ALD & 0,20 & 5,00 & 20 & 25 & 8 & 8 \\
\hline M3 & $\begin{array}{l}\text { Service } \\
\text { Station }\end{array}$ & 7,20 & 9,00 & 18 & 20 & 8 & 10 \\
\hline M4 & $\begin{array}{l}\text { Power } \\
\text { Supply }\end{array}$ & 62,70 & 10,00 & 7 & 15 & 7 & 10 \\
\hline M5 & Modem & 5,80 & 6,00 & 9 & 14 & 4 & 6 \\
\hline M6 & $\begin{array}{l}\text { Main } \\
\text { Board }\end{array}$ & 22,10 & 5,00 & 7 & 11 & 3 & 6 \\
\hline M7 & $\begin{array}{l}\text { Main } \\
\text { Motor }\end{array}$ & 0,20 & 14,00 & 21 & 30 & 10 & 15 \\
\hline M8 & $\begin{array}{c}\text { Top } \\
\text { Module }\end{array}$ & 0,7 & 7 & 15 & 15 & 6 & 10 \\
\hline M9 & $\begin{array}{l}\text { Lower } \\
\text { Module }\end{array}$ & 1,1 & 5,5 & 17 & 20 & 9 & 9 \\
\hline M10 & $\begin{array}{l}\text { Lower } \\
\text { Housing }\end{array}$ & 0,2 & 4 & 50 & 50 & 4 & 8 \\
\hline M11 & Cover & 0,7 & 5 & 50 & 50 & 4 & 6 \\
\hline
\end{tabular}

Table 1 : Input data table for Modular Grouping Explorer.

\subsection{Validation of remanufacturability}

Then the reliability and obsolescence of the pMR are verified. The class of the 11 modules of the product is defined in Table 2.

\begin{tabular}{|c|l|c|c|c|}
\hline Modules & Class & Reliability fraction & Value fraction & Validation Class \\
\hline User Interface & pMR & 66,67 & 40 & pMR \\
ALD & pMU & 75,00 & 80 & pMU \\
Service Station & pMU & 58,33 & 80 & pMU \\
Power Supply & pMR & 66,67 & 70 & pMR \\
Modem & pMU & 50,00 & 40 & pMU \\
Main Board & pMR & 41,67 & 30 & pMR \\
Main Motor & pMU & 83,33 & 100 & pMU \\
Top Module & pM_rr & 58,33 & 60 & pM_rr \\
Lower Module & pM_rr & 66,67 & 90 & pM_rr \\
Lower Housing & pM_rr & 100,00 & 40 & pM_rr \\
Cover & pM_rr & 100,00 & 40 & pM_rr \\
\hline
\end{tabular}

Table 2 : Definition of Modules End of Life.

\subsection{Modular grouping by Affinity calculation}

The following stage consists in establishing $\mathrm{pMR} / \mathrm{pMR}, \mathrm{pMr} / \mathrm{pMr}$, $\mathrm{pMU} / \mathrm{pMR}$, pMU/pMr grouping according to reliability and obsolescence affinity. The table below is a sample of the affinity calculation between module $\mathrm{UI}$ and the 10 other modules. The modules with same class and having an affinity higher or equal to $80 \%$ are likely to be gathered within the same module.

The designer validates or not in regarding technical and functional compatibility. For the modules whose affinity is lower than $80 \%$, tool MGE calculates a potential affinity using BEST MTBF and BEST VLT introduced in INPUT. Finally when a couple $\mathrm{pMU} / \mathrm{pMX}$ or $\mathrm{pMX} / \mathrm{pMX}$ (with $\mathrm{X}=\mathrm{R}$ or $\mathrm{R}$ ) does not fill the criteria, there are a stage of iteration with decomposition of the module pMU and/or pMX Submodules when it's possible. 


\begin{tabular}{|c|c|c|c|}
\hline Modules & & \multicolumn{2}{|c|}{ User Interface } \\
\hline & Class & \multicolumn{2}{|c|}{ pMR } \\
\hline User Interface & pMR & & \\
\hline ALD & $\mathrm{pMU}$ & $80 \%$ & $80 \%$ \\
\hline Service Station & pMU & $72 \%$ & $80 \%$ \\
\hline Power Supply & pMR & $28 \%$ & $70 \%$ \\
\hline Modem & $\mathrm{pMU}$ & $36 \%$ & $40 \%$ \\
\hline Main Board & pMR & $28 \%$ & $30 \%$ \\
\hline Main Motor & $\mathrm{pMU}$ & $84 \%$ & $100 \%$ \\
\hline Top Module & $\mathrm{pM} r$ & $60 \%$ & $60 \%$ \\
\hline Lower Module & $\mathrm{pM} \mathrm{r}$ & $68 \%$ & $90 \%$ \\
\hline Lower Housing & $\mathrm{pM} r$ & $50 \%$ & $40 \%$ \\
\hline Cover & $\mathrm{pM} r$ & $50 \%$ & $40 \%$ \\
\hline & & $A_{\text {fiab }}$ & $A_{\text {obs }}$ \\
\hline
\end{tabular}

Table 3 : Affinity calculation.

\subsection{Evaluation Of Product Architectures}

Five architectures are evaluated, corresponding to different strategies: (strategy economic, environmental, mixed and different levels from reliability and obsolescence).

The procedure of evaluation will be detailed for the first list.

1. The designer defines the modules organization within the product and defines connections between modules.

\begin{tabular}{|c|c|c|c|c|c|}
\hline Iv & Solution 1 & Solution 2 & Solution 3 & Solution 4 & Solution 5 \\
\hline 1 & $M_{1}^{\prime}=M_{10}+M_{11}$ & $M_{1}^{\prime}=M_{1}$ & $\begin{array}{l}M_{1}^{\prime}=M_{10}+M_{11} \\
M_{2}^{\prime}=M_{1}+M_{2}\end{array}$ & $M_{1}^{\prime}=M_{10}+M_{11}$ & $M_{1}^{\prime}=M_{10}+M_{11}$ \\
\hline 2 & $\begin{array}{c}M_{2}^{\prime}=M_{1}+M_{4}+M \\
5+M_{6}\end{array}$ & $\begin{array}{l}M_{2}^{\prime}=M_{2}+M_{10}+ \\
M_{11}\end{array}$ & $\mathrm{M}_{3}^{\prime}=\mathrm{M}_{3}+\mathrm{M}_{4}$ & $\mathrm{M}_{2}^{\prime}=\mathrm{M}_{1}+\mathrm{M}_{3}$ & $\begin{array}{l}\mathrm{M}_{2}^{\prime}=\mathrm{M}_{1}+\mathrm{M}_{2}+ \\
\mathrm{M}_{4}\end{array}$ \\
\hline 3 & $\begin{array}{l}\mathrm{M}_{3}^{\prime}=\mathrm{M}_{2}+\mathrm{M}_{8} \\
\mathrm{M}_{4}=\mathrm{M}_{3}\end{array}$ & $M_{3}^{\prime}=M_{5}+M_{6}$ & $\mathrm{M}_{4}^{\prime}=\mathrm{M}_{5}+\mathrm{M}_{6}$ & $\mathrm{M}_{3}^{\prime}=\mathrm{M}_{5}+\mathrm{M}_{6}$ & $\begin{array}{l}M_{3}^{\prime}=M_{3}+M_{8}+ \\
M_{9} \\
M_{4}^{\prime}=M_{5}+M_{6} \\
M_{5}^{\prime}=M_{7}\end{array}$ \\
\hline 4 & $\begin{array}{l}M_{5}^{\prime}=M_{9} \\
M_{6}^{\prime}=M_{7}\end{array}$ & $\mathrm{M}_{4}^{\prime}=\mathrm{M}_{3}+\mathrm{M}_{8}$ & $\begin{array}{l}\mathrm{M}_{5}^{\prime}=\mathrm{M}_{7}+\mathrm{M}_{9} \\
\mathrm{M}_{6}^{\prime}=\mathrm{M}_{8}\end{array}$ & $\begin{array}{l}\mathrm{M}_{4}^{\prime}=\mathrm{M}_{2}+\mathrm{M}_{4} \\
\mathrm{M}_{5}^{\prime}=\mathrm{M}_{7}\end{array}$ & \\
\hline 5 & & $\begin{array}{l}M_{5}^{\prime}=M_{4}+M_{7} \\
M_{6}^{\prime}=M_{9}\end{array}$ & & $M_{6}^{\prime}=M_{8}+M_{9}$ & \\
\hline
\end{tabular}

Table 4 : Potential solutions of Product Architecture defined by MGE.

2. Modeling of the dismantling sequence on Prodtect.

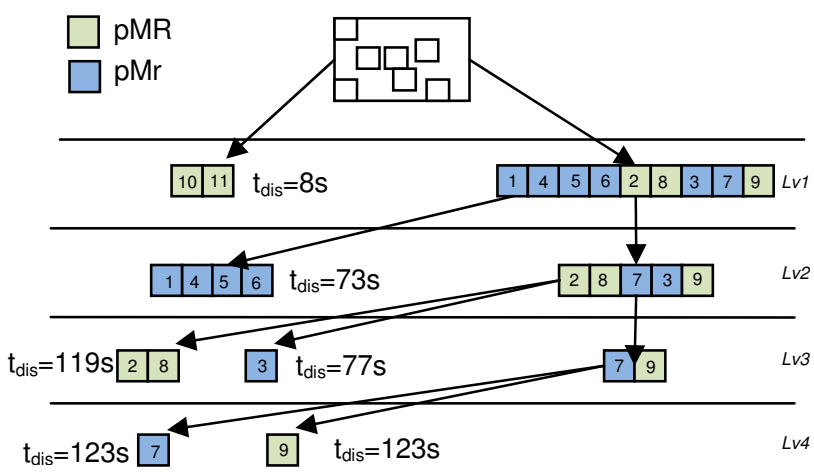

Figure 4 : Dismantling sequence.

3. Time and cost for pMR extraction

\begin{tabular}{|c|c|c|c|c|c|}
\hline $\begin{array}{l}\text { From } \\
\text { Module } 1\end{array}$ & \begin{tabular}{|l|} 
To \\
Module 2 \\
\end{tabular} & $\begin{array}{l}\text { Type de } \\
\text { fixation }\end{array}$ & $\begin{array}{l}\text { Nombre de } \\
\text { fixation }\end{array}$ & $\begin{array}{l}\text { Direction de } \\
\text { désassemblage }\end{array}$ & $t(s)$ \\
\hline $\bar{M}{ }^{\prime} 1$ & M'2 & Snap fit & 4 & $+\mathrm{X}$ & 8,42 \\
\hline M'2 & M'3 & Screw & 4 & $+\mathrm{X}$ & \multirow{3}{*}{64,46} \\
\hline M'2 & M'3 & Screw & 2 & $+Y$ & \\
\hline M'2 & M'3 & Screw & 2 & $-Y$ & \\
\hline M'2 & $M^{\prime} 4$ & Snap fit & 1 & $+\mathrm{X}$ & 1,84 \\
\hline M'3 & M'4 & Snap fit & 1 & $+Y$ & 4,86 \\
\hline M'3 & M'5 & Screw & 4 & $-X$ & 35 \\
\hline M'3 & M'6 & Snap fit & 1 & $+Y$ & 4,86 \\
\hline $\mathrm{M}^{\prime} 4$ & $\begin{array}{ll}\text { M'5 } \\
\end{array}$ & Screw & 1 & $+Y$ & 1,84 \\
\hline M'5 & $M^{\prime} 6$ & Screw & 2 & $+\mathrm{X}$ & 1.84 \\
\hline
\end{tabular}

Table 5 : Potential solutions of Product Architecture defined.
The calculation of disassembly cost is based on an hourly wage with $49 € / h$ (tax included).

4. Calculation of the recovered value and the losses for the manufacture of a new machine (Table 6 )

$\mathrm{G}_{\mathrm{pMR}}=\mathrm{P}_{\mathrm{r}}-\mathrm{C}_{\text {dis }}$ and $\mathrm{L}_{\mathrm{pMr}}=\mathrm{P}_{\mathrm{r}}+\mathrm{C}_{\text {dis }}$

\begin{tabular}{|c|c|c|c|c|c|c|c|c|}
\hline Modules & EoL & $\begin{array}{l}t_{\text {dis }} \\
(\mathbf{s})\end{array}$ & $\begin{array}{l}C_{\text {dis }} \\
(\epsilon)\end{array}$ & $\begin{array}{l}P_{r} \\
(€)\end{array}$ & $\begin{array}{l}\text { Recovered } \\
\text { Value }(€)\end{array}$ & \begin{tabular}{|l} 
Loss \\
Value $(€)$
\end{tabular} & $\begin{array}{l}\text { Avoided } \\
\text { Impact } \\
\text { (Pts) }\end{array}$ & \begin{tabular}{|l} 
Generated \\
impacts \\
(Pts)
\end{tabular} \\
\hline $\mathrm{M}^{\prime} 1$ & $\mathrm{pMr}$ & 8,4 & 0,11 & 9 & & 9,11 & & 0,9 \\
\hline M'2 & MR & 74,7 & 1,02 & 33 & 31,98 & & & \\
\hline M'3 & $\mathrm{Mr}$ & 119,4 & 1,63 & 12 & & 13,63 & & 0,9 \\
\hline M'4 & pMR & 76,6 & 1,04 & 9 & 7,96 & & 7,2 & \\
\hline M'5 & $\mathrm{pMr}$ & \begin{tabular}{|l|}
123,1 \\
\end{tabular} & 0 & 5,5 & & 5,5 & & 1,1 \\
\hline M'6 & pMR & 123,1 & 1,68 & 7 & 5,32 & & 0,2 & \\
\hline
\end{tabular}

Table 6 : Economic and Environmental data per Modules for solution1.

An economic gain is considered when pMR are extracted, whereas for the pMr the profits generated by the resale of materials to the recyclers are neglected. In the case study the resale of pMR compensates for the transport costs [28]. When a pMr is found at the end of the dismantling sequence the disassembly cost is null (Cdis=0).

5. Calculation of the avoided impacts and the pollution generated during materials extraction and manufacture of a new machine (Table 6).

6. Choice of the best Product Architectures

The current scenario is modeled by taking the current Product Architecture with the dismantling process carried out in experiments. The end-of-life scenario for modules is defined table 3 , i.e. M1, M4 and M6 are remanufactured and other modules are recycled or discarded.

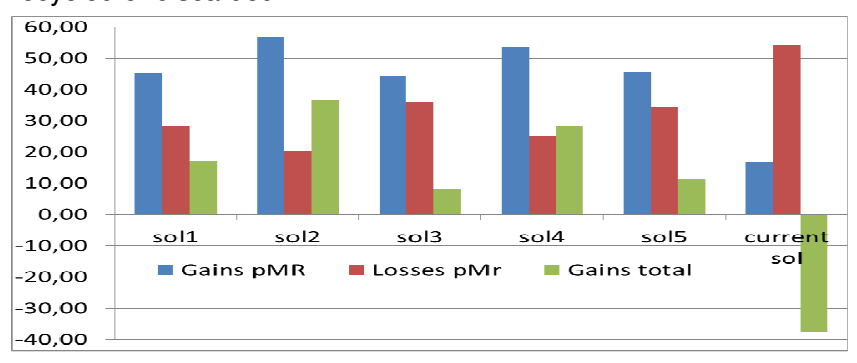

Figure 5 : Economic Assessment for each Solution.

Economically there are more or less important disparities between the solutions (

Figure 5). The dismantling of the current product cost approximately $40 €$. The best solution is solution 2 with a profit of $38 €$.

From an environmental point of view the results are contrasted (

Figure 6), indeed the performances of solutions from 1 to 4 are overall identical because the same modules are recovered for remanufacturing. The environmental performance of current product is less good because only three modules are remanufactured.

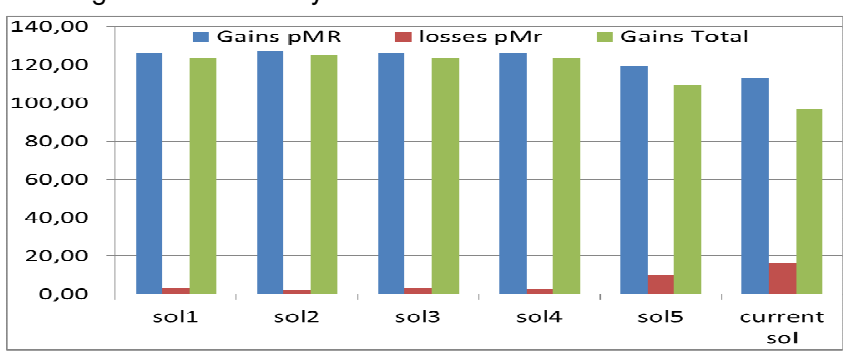

Figure 6 : Environmental Assessment for each Solution. 


\section{CONCLUSION}

The approach suggested in this article and materialized by a tool MGE allows to pre-define Modules in early phases of design process. These modules are made up in order to optimize the endof-life, by gathering the modules according to the characteristics of their life cycle. The groupings take into account the physical characteristics (reliability) of the components as well as the obsolescence of the components throughout life cycle (VLT). This approach was tested on a B2B product "A Franking Machine" with the goal to design a modular architecture remanufacturable. The tool determines a variety of solutions classified economically and environmentally.

This tool is part of a more comprehensive methodology integrating the definition of Upgrade cycles, structure of Reverse Supply Chain and allowing the activities of remanufacturing economically viable while taking into account environmental and social considerations.

\section{ACKNOWLEDGMENTS}

This work was financially supported by ADEME and CETIM foundation in the framework of MacPMR research program. We thank them.

\section{REFERENCES}

[1] Lund, R.T., (1996), The Remanufacturing Industry: Hidden Giant. Boston. Boston: Argonne National Laboratory study.

[2] Ijomah, W.L., (2002), A model-based definition of the generic remanufacturing business process. University of Plymouth.

[3] Steinhilper R., (1998), Remanufacturing - The Ultimate Form of Recycling: Fraunhofer IRB Verlag, Stuttgart.

[4] Sundin E., (2004), Product and Process Design for Successful Remanufacturing. Department of Mechanical Engineering. Linköping, Sweden: Linköping University.

[5] Umeda Y, Fukushige S, Tonoike K, Kondoh S., (2008), Product modularity for life cycle design. CIRP Annals Manufacturing Technology, 57, pp.13-16.

[6] Van der Laan, E., Salomon, M., (1997), Production planning and inventory control with remanufacturing and disposal. European Journal Of Operational Research, 102, pp.264-278.

[7] Ijomah, W.L., McMahon, C.A., Hammond, G.P., Newman, S.T., (2007), Development of design for remanufacturing guidelines to support sustainable manufacturing. Robotics and Computer-Integrated Manufacturing, 23, pp.712-719.

[8] Duflou, J.R., Seliger, G., Kara, S., Umeda, Y., Ometto, A., Willems, B., (2008), Efficiency and feasibility of product disassembly: A case-based study. Paper presented at the CIRP Annals - Manufacturing Technology.

[9] Gehin A., (2008), Développement d'une Méthodologie de Conception de Produits Durables. PhD Thesis INPG Génie Industriel.

[10] Kerr W., (1999), Remanufacturing and eco-efficiency: A case study of photocopier remanufacturing at Fuji Xerox Australia. International Institute for Industrial Environmental Economics: Lund University, Sweden.

[11] Mont, O., Dalhammar, C., Jacobsson, N., (2006), A new business model for baby prams based on leasing and product remanufacturing. Journal of Cleaner Production, 14(17), pp.1509-1518.

[12] Gungor A, Gupta S M., (1997), An evaluation methodology for disassembly process. Computers \&Industrial Engineering, 33, pp.329-332.
[13] Lambert A. J. D., (2002), Determining Optimum Disassembly Sequences In Electronic Equipment. Computers \&Industrial Engineering, 43, pp.553-575.

[14] Desai, A., Mital, A., (2003), Evaluation of disassemblability to enable design for disassembly in mass production. International Journal of Industrial Ergonomics, pp.32, 265281.

[15] Kara S, Pornprasitpol P, H. Kaebernick H., (2006), Selective Disassembly Sequencing: A Methodology for the Disassembly of End-of-Life Products. Annals of CIRP, 55, pp1-4.

[16] Zuidwijk R, Krikke H., (2007), Strategic Response to EEE Returns: Product Eco-Design Or New Recovery Process? European Journal of Operational Research, 191, pp.12061222.

[17] Seliger G, Zettl M., (2008), Modularization as an enabler for cycle economy. Annals of CIRP - Manufacturing Technology, 57, pp.133- 136.

[18] Kimura F, Kato S, Hata T, Masuda T., (2001), Product modularization for parts Reuse in inverse manufacturing. Annals of CIRP, 50, pp.89-92.

[19] Tomiyama, T., Sakao, T., Umeda, Y., (2005), The Post Mass Production Paradigm, Knowledge Intensive Engineering, and Soft Machine. In International Conference on Life Cycle Modelling for Innovative Products and Processes. Berlin.

[20] Kondoh, S., Umeda, S., Yoshikawa H., (1998), Development of Upgradable Cellular Machines for Environmentally Conscious Products. Annals of CIRP, 47(1).

[21] Tchertchian, N., Liang, H., Millet, D., (2009), The Influence of the Multiple Life Cycles on the Environmental Impact of a Product. Proc. ICED 2009 17th Int. Conf. Engineering Design.

[22] Ulrich, K. T., (1995), The role of product architecture in the manufacturing firm, Research Policy. 24: 419-440.

[23] Erens, F. Verhulst, K., (1997), Architectures for product families. Computers in Industry, 33, 165-178.

[24] Fixson, S.K., (2005), Product architecture assessment: a tool to link product, process, and supply chain design decisions. Journal of Operations Management. v23. 345-369.

[25] Tchertchian, N., Millet D., El Korchi A., (2010), A method helping to define eco-innovative systems (product architecture + RSC structure + scenario usage). 17th CIRP International Conference on Life Cycle Engineering, Hefei.

[26] Tseng H.-E., Chang C.-C., Li J.-D., Modular design to support green life-cycle engineering. Expert Systems with Applications,34:25, 24-37, 2008.

[27] Pialot, O., Millet D., Tchertchian, N., (2010), Definition of potential upgrade scenario in early design phases of remanufacturable system. Proceedings of IDMME - Virtual Concept Bordeaux, 2010.

[28] El Korchi, A., (2010), Conditions stratégiques d'émergence d'une reverse supply chain fondée sur le remanufacturing chez le fabricant d'origine, The 8th International Conference on Logistics and SCM Research, Bordeaux, 2010.

\section{Contact}

Nicolas Tchertchian

Supmeca toulon, LISMMA laboratory,

Maison des technologies, 83000 Toulon, France,

nicolas.tchertchian@supmeca.fr 